Provided for non-commercial research and education use. Not for reproduction, distribution or commercial use.

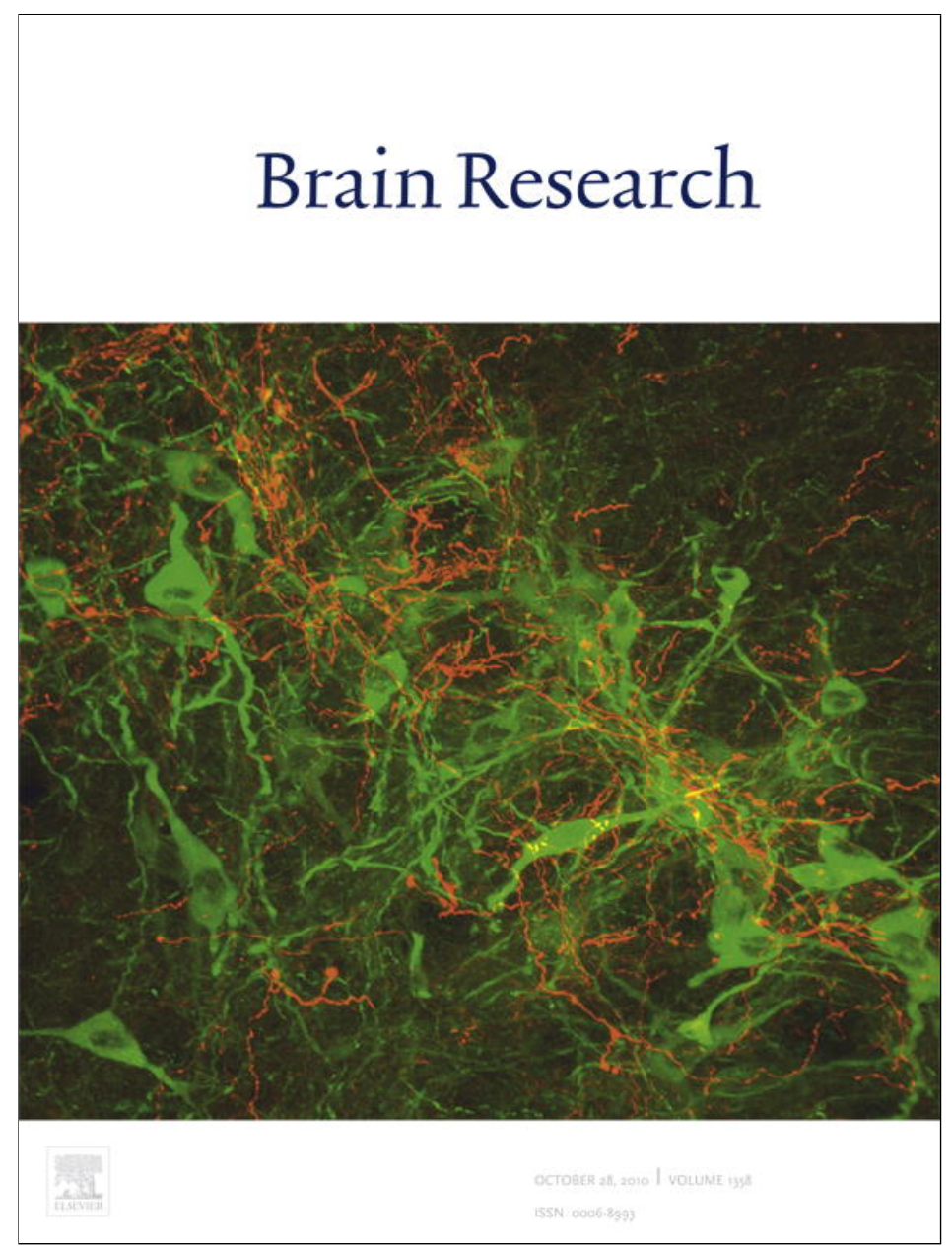

This article appeared in a journal published by Elsevier. The attached copy is furnished to the author for internal non-commercial research and education use, including for instruction at the authors institution and sharing with colleagues.

Other uses, including reproduction and distribution, or selling or licensing copies, or posting to personal, institutional or third party websites are prohibited.

In most cases authors are permitted to post their version of the article (e.g. in Word or Tex form) to their personal website or institutional repository. Authors requiring further information regarding Elsevier's archiving and manuscript policies are encouraged to visit:

http://www.elsevier.com/copyright 
Research Report

\title{
FGF-2/FGFR1 neurotrophic system expression level and its basal activation do not account for the age-dependent decline of precursor cell proliferation in the subventricular zone of rat brain
}

\author{
Monica Frinchi ${ }^{a, 1}$, Valentina Di Liberto ${ }^{a, 1}$, Melania Olivieri ${ }^{a}$, Kjell Fuxe ${ }^{b}$, \\ Natale Belluardo ${ }^{a, 1}$, Giuseppa Mudò ${ }^{a, *, 1}$ \\ ${ }^{a}$ Department of Experimental Biomedicine and Clinical Neuroscience, div. Human Physiology, Laboratory of Molecular Neurobiology, \\ University of Palermo, corso Tukory 129, IT-90134 Palermo, Italy \\ ${ }^{b}$ Department of Neuroscience, Karolinska Institute, Retzius väg 8, 17177 Stockholm, Sweden
}

\section{A R T I C L E I N F O}

Article history:

Accepted 25 August 2010

Available online 18 September 2010

\section{Keywords:}

FGF-2

FGFR1

Neurogenesis

Subventricular zone

Neuronal precursor cells

Aging

\begin{abstract}
A B S T R A C T
It is largely accepted that neurogenesis in the adult brain decreases with age and reduced levels of local neurotrophic support is speculated to be a contributing factor. Among neurotrophic factors involved on neurogenesis, we focused our attention on the neurotrophic system fibroblast growth factor-2 (FGF-2) and its receptor FGFR1, a potent modulator of precursor cell proliferation. In the present work, we aimed to analyse if potential age-dependent changes of the FGF-2/FGFR1 neurotrophic system may give account for the age-dependent decline of precursor cell proliferation in the neurogenic region of the subventricular zone (SVZ) in the rat brain. Using in situ hybridization and western blotting procedures we examined FGF-2 and FGFR1 expression levels in the SVZ of 20-month-old rats as compared to young adult 3-month-old rats. The results showed that during aging the FGF-2 and its receptor expression levels, both as mRNA and protein, were unchanged in the SVZ. The levels of phosphorylated FGFR1 form did not show significant variations suggesting that also the level of receptor activation does not change during aging. No changes were also observed in the phosphorylation of two FGFR1 related proteins involved in intracellular signaling, the canonical extracellular signal-regulated kinase Erk1/2 and the phospholipase-C $\gamma 1$. Additionally, we could show that also the proliferation rate of stem cells does not change during aging. Taken together, our results show that FGF-2/FGFR1 neurotrophic system expression level and its basal activation do not account for the agedependent decline of precursor cell proliferation in the rat brain.
\end{abstract}

() 2010 Elsevier B.V. All rights reserved.

\footnotetext{
* Corresponding author. Fax: +39091 23860714.

E-mail address: g.mudo@unipa.it (G. Mudò).

Abbreviations: SVZ, subventricular zone; BrdU, bromodeoxyuridine; FGF-2, fibroblast growth factor-2

${ }^{1}$ MF and VDL, NB and GM contributed equally to this work.
}

0006-8993/\$ - see front matter @ 2010 Elsevier B.V. All rights reserved. doi:10.1016/j.brainres.2010.08.083 


\section{1.}

\section{Introduction}

There are two active germinal zones in the adult brain that continue to generate neurons throughout adult life: the subventricular zone (SVZ) of the lateral ventricles and the subgranular zone of the dentate gyrus of the hippocampus (Abrous et al., 2005; Doetsch et al., 1999; Zhao et al., 2008). It is largely accepted that the proliferation rate of progenitor/precursor cells and neuroblast numbers or ratio of cells differentiating into neurons decrease with age (Belluardo et al., 2008; Cameron and McKay, 1999; Hattiangady and Shetty, 2008; Jin et al., 2003; Maslov et al., 2004; Rao et al., 2006; Tropepe et al., 1997). The precise reasons for age-related reductions in neuronal precursor cell proliferation are not yet clear, but reduced levels of trophic support is speculated to be a contributing factor (Hallbergson et al., 2003). Among neurotrophic factors potentially involved on aged-dependent decline of progenitor/precursor cell proliferation we focused our attention on the neurotrophic system of fibroblast growth factor-2 (FGF-2) and its receptor FGFR1, that has been extensively studied and found to be a potent modulator of adult neuronal progenitor/precursor cells proliferation and differentiation in the SVZ (Mudo et al., 2007; Ohkubo et al., 2004; Wagner et al., 1999; Yoshimura et al., 2001). In apparent support of FGF-2 involvement in aged-dependent decline of progenitor/ precursor cells proliferation, it has been reported that intracerebroventricular infusion of FGF2 restores progenitor/precursor cells proliferation in aged brain to levels found in young adult brain (Jin et al., 2003). Previously, we reported that in the SVZ of old rats an age-dependent decline of precursor cells proliferation can be restored to levels found in young adult rats by enhancing FGF-2 with acute-intermittent nicotine treatment (Belluardo et al., 2008). However, there are no available data on agedependent change of FGF-2/FGFR1 neurotrophic system expression levels and on its basal activation in the SVZ of rat brain.

In this work, as an extension of two previous studies on the role of the FGF-2/FGFR1 neurotrophic system in precursor cells proliferation both in the adult and old rat brain (Belluardo et al., 2008; Mudo et al., 2007), we aimed to investigate if age related changes of FGF-2/FGFR1 neurotrophic system expression levels or FGFR1 basal activation may give account for the age-related decline of precursor cell proliferation in the SVZ neurogenic region of rat brain. To this end, we first analysed, by in situ hybridization and western blotting procedures, the FGF-2/FGFR1 neurotrophic system expression levels in the SVZ of 20 month old rats as compared to 3 month old rats. Subsequently, we examined the FGFR1 basal activation by evaluating the levels of FGFR1 autophoshorylation (pFGFR1), and phosphorylation of two related intracellular signaling proteins, the canonical extracellular signal-regulated kinase, Erk1/2 (pErk1/2) and phospholipaseC $\gamma 1$ (pPLC $\gamma 1$ ) (Mohammadi et al., 1992; Schlessinger, 2000).

\section{Results}

\subsection{FGF-2 and FGFR-1 mRNA expression levels}

Using in situ hybridization, both FGF-2 and FGFR1 mRNAs were found expressed at relatively high levels in the SVZ of the lateral ventricle (Fig. 1). The densitometric analysis revealed no changes of FGF-2 and FGFR1 mRNA expression levels in the SVZ of old rats as compared to young adult rats $(P=0.91$ and $P=0.83$ respectively; Fig. 1).

\subsection{FGF-2 protein levels}

Dissected tissue from SVZ of the lateral ventricle showed immunoreactive bands corresponding to FGF-2 isoforms with molecular weights of 18, 21, $22 \mathrm{kDa}$. As reported in Fig. 2, in old rats the FGF-2 levels did not show significant variations as compared to those of young adult rats $(18 \mathrm{kDa}, P=0.88 ; 21 \mathrm{kDa}$, $P=0.50 ; 22 \mathrm{kDa}, P=0.31$ ).

\subsection{FGFR1, Erk1/2, and PLC $\boldsymbol{\gamma} 1$ phosphorylation levels}

In order to evaluate the basal level of FGFR1 activation during aging we quantified the levels of the autophosphorylated form of FGFR1 (p-FGFR1). Using immunoprecipitation procedure and subsequent detection of total tyrosine kinase activity with antityrosine kinase antibodies, we performed a quantification of the pFGFR1 levels in the SVZ. As reported in Fig. 3 the levels of p-FGFR1 did not show significant variation $(P=0.72)$, suggesting that during aging the basal receptor activation does not change in the SVZ. No significant modification was also observed in the relative FGFR1 protein levels evaluated by quantification of western blot data shown in Fig. 3 (young, 1.2 \pm 0.24 ; old, 1.3 \pm 0.14 ; $P=0.54$ ) and obtained by immunoprecipitation of the same amount of total proteins $(150 \mu \mathrm{g})$.

Previous studies (Mohammadi et al., 1992; Schlessinger, 2000) have identified for FGFR1 two key intracellular signaling pathways, Erk1/2 and PLC $\gamma 1$ pathways, that regulate distinct aspects of adult neuronal stem cells in response to FGF-2. Therefore, we examined the ERK1/2 and PLC 1 phosphorylation levels and found them to be not modified during aging ( $P=0.98$ and $P=0.50$, respectively) (Fig. 3).

\subsection{Proliferating self-renewing progenitor cells number}

It has been reported that in the SVZ the progenitor cells are selfrenewing cells (B-cells), and therefore, when labeled with bromodeoxyuridine (BrdU), they can be found in the SVZ even several weeks after BrdU injection. In contrast, BrdU-labeled cells of differentiating precursor cells (A-cells), which are generated by rapidly proliferating transiently amplifying cells (C-cells), migrate within 3 weeks toward the migratory stream depopulating the SVZ. Since FGFR1 was found expressed both in B cells and in C cells (Belluardo et al., 2008; Frinchi et al., 2008; Mudo et al., 2007), and the declined neurogenesis during aging has been also attributed to a reduced number or proliferation rate of progenitor cells (Jin et al., 2003; Luo et al., 2006; Maslov et al., 2004), we decided to evaluate the proliferating selfrenewing progenitor cell number in the SVZ. Rats were treated intraperitoneally for three times (at 0, 12, $24 \mathrm{~h}$ ) with $80 \mathrm{mg} / \mathrm{kg}$ i.p. of BrdU and were sacrificed after 21 days, in order to evaluate the BrdU-labeled cells left in the SVZ after depopulation of BrdU labeled cells migrating in the olfactory bulbs. The number of these BrdU-positive cells in the SVZ of aged rats was found similar to that of young rats $(P=0.80)$ (Fig. 4), suggesting that reduced proliferation of progenitor cells does not account for the decline of SVZ neurogenesis during aging. 

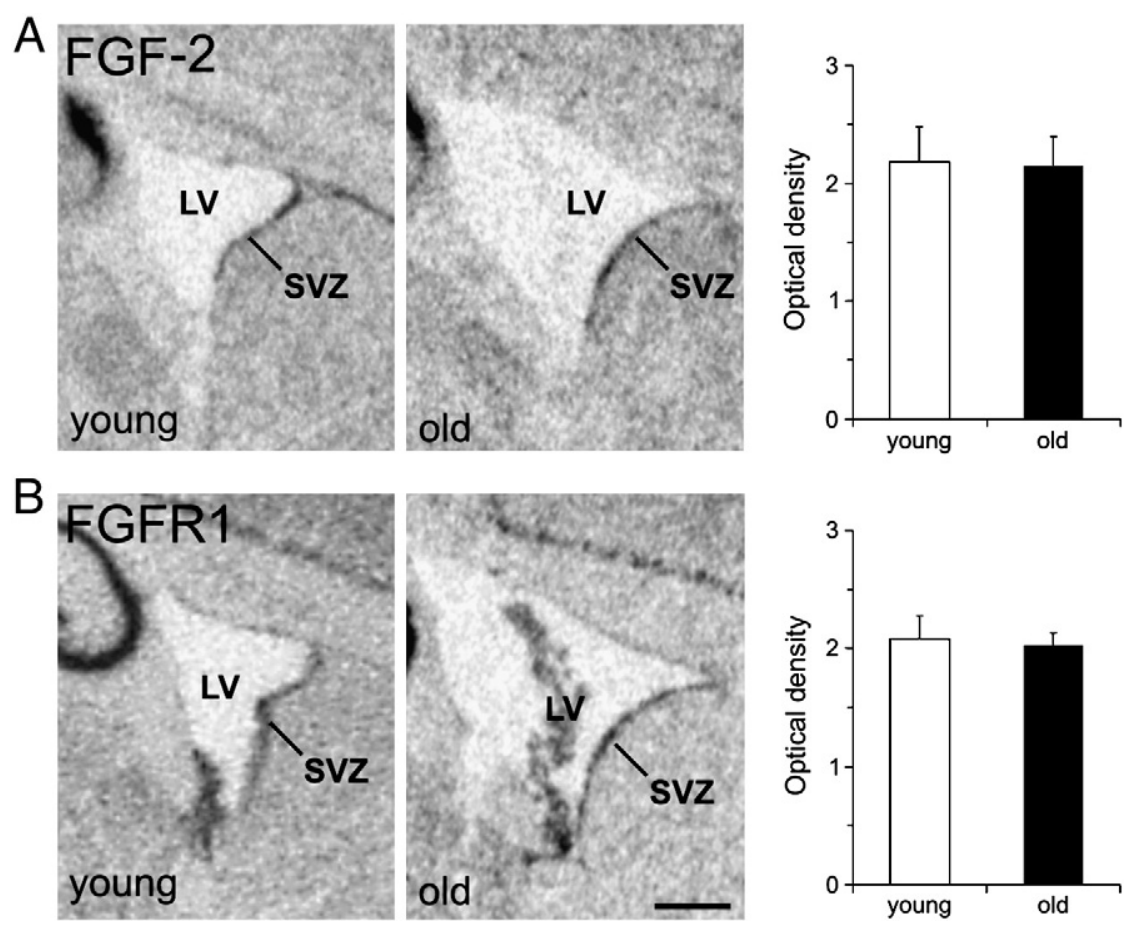

Fig. 1 - In situ hybridization showing FGF-2 (A) and FGFR1 (B) mRNA expression in the subventricular zone (SVZ) of lateral ventricle (LV) in sagittal brain sections of young adult and old rats. Histograms show FGF-2 and FGFR1 mRNA levels in young adult rats as compared to old rats evaluated by measuring on the film autoradiograms the relative FGF-2 and FGFR1 mRNA labeling along the entire lateral wall of the lateral ventricle. Data are shown as means \pm SEM. Scale bars: $500 \mu \mathrm{m}$.
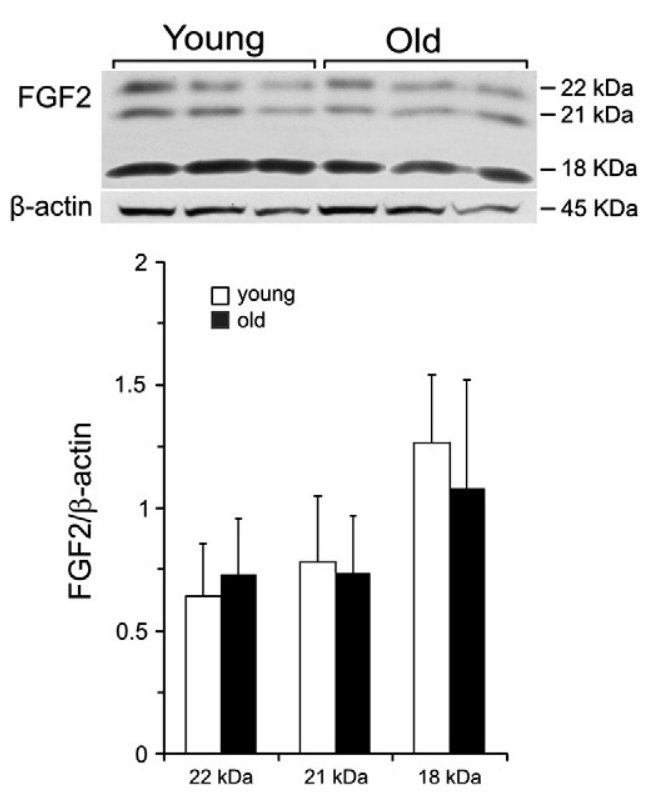

Fig. 2 - Western blot analysis of FGF-2 levels in dissected tissue from the subventricular zone of lateral ventricle of young adult and old rats. Immunoreactivity of FGF-2 was detected as 18, $2122 \mathrm{kDa}$ bands, corresponding to FGF-2 protein isoforms. Internal standard $\beta$-actin was used for the quantitative evaluation of FGF-2 levels. Data are means of optical density (OD) values obtained from films and expressed as arbitrary units.

\section{Discussion}

The SVZ consists of a thin layer of cells in active proliferation throughout adulthood, covering the walls of the lateral ventricles (Abrous et al., 2005; Doetsch et al., 1999; Garcia-Verdugo et al., 1998; Zhao et al., 2008). The analysis of precursor cell types in the adult SVZ showed a multiciliated ependymal cells (type E) in direct contact with the lumen of the ventricle, and a special population of astrocytes (B-cells) in close contact with the ependyma, labeled by nestin, GFAP, and vimentin and considered to be neuronal stem cells. Besides symmetric divisions, Bcells generate actively proliferating cells or "transient amplifying progenitors" (C-cells). C-cells give rise to a third type of precursors (A-cells) that migrate through the rostral migratory stream toward the olfactory bulb, where they differentiate mainly into neuronal cells in the granular and periglomerular layers. Research, in vitro and in vivo, has produced a substantial body of knowledge showing that progenitor and precursor cells in the germinal zones of adult brain require growth factors for cell proliferation and differentiation (Abrous et al., 2005; Chen et al., 2007; Craig et al., 1996; Kuhn et al., 1997). The FGF2/FGFR1 neurotrophic system has been extensively studied and found to be a potent modulator of adult neuronal progenitor/precursor cells proliferation and differentiation in the SVZ (Mudo et al., 2007; Ohkubo et al., 2004; Wagner et al., 1999; Yoshimura et al., 2001). FGF2 has been implicated in the control of adult neurogenesis based on effects on maintenance, proliferation 


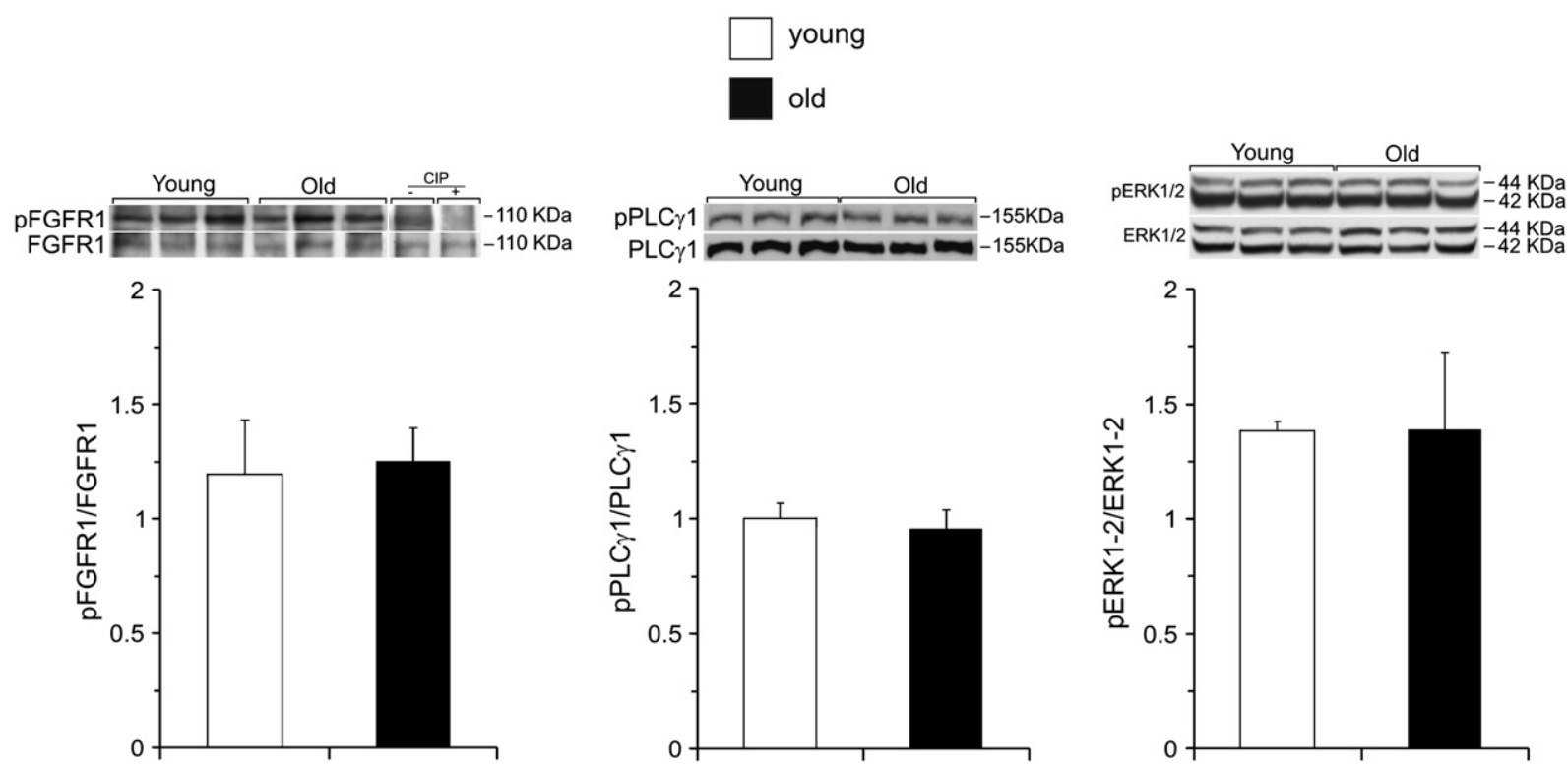

Fig. 3 - Western blotting analysis in dissected tissue from subventricular zone of lateral ventricle of young adult and old rats. Evaluation of phosphorylated and unphosphorylated forms for FGFR1/pFGFR1; Erk1/2/pErk1/2; PLC $\gamma 1 /$ pPLC $\gamma 1$. Histograms show the levels of western blot data calculated by densitometry of the immunoreactive bands and are expressed as the ratio of phosphorylated and unphosphorylated forms. In order to determine if the antibody anti-phosphotyrosin used for detection of pFGFR1 binds phosphorylated FGFR1 protein, sister membrane with representative samples were incubated $\mathrm{O} / \mathrm{N}$ at $37^{\circ} \mathrm{C}$ with or without $1 \%$ calf intestinal alkaline phosphatase (CIP). Note in the western blot data for FGFR1/pFGFR1, the disappearance of pFGFR1 band in presence of CIP (+CIP) as compared to control sister band without CIP (-CIP), suggesting the specific detection of phosphorylated FGFR1 protein. Data are means of optical density (OD) values obtained from films and expressed as arbitrary units.

and fate of adult multipotent neural progenitor (Gritti et al., 1999; Richards et al., 1992; Zheng et al., 2004), and infusion or induction of FGF2 in the adult rat lateral ventricle increased

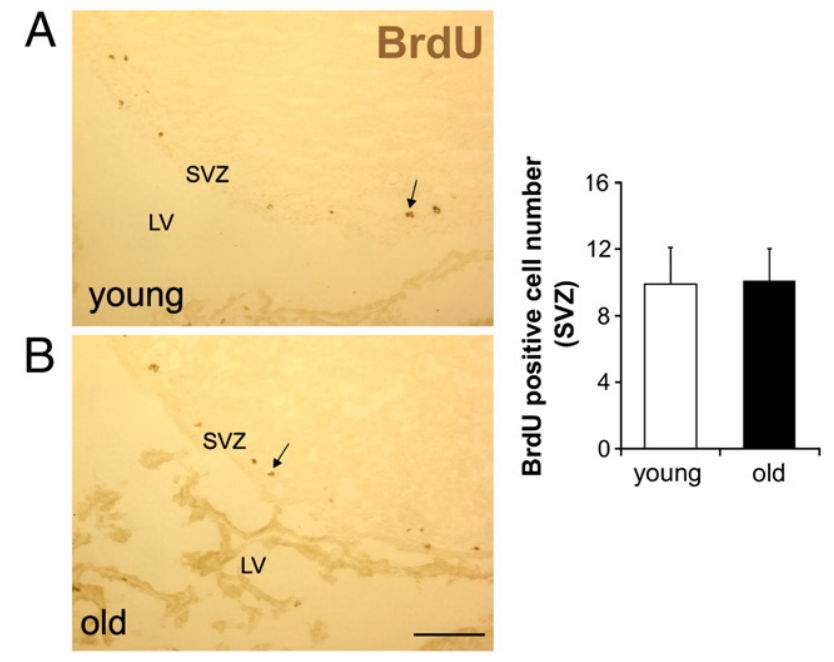

Fig. 4 - Analysis of BrdU labeled cells in the subventricular zone (SVZ) of lateral ventricle (LV) 21 days after BrdU injection. (A and B) Representative photomicrograph of SVZ from sagittal brain sections of young adult (A) and old (B) rats showing BrdU labeled cells (arrows) along the entire lateral wall of the lateral ventricle. Histogram showing evaluation of BrdU labeled cell number in young adult rats as compared to old rats. Scale bar: $100 \mu \mathrm{m}$. proliferating cells in the SVZ with a subsequent increase in the number of neurons migrating from the SVZ to the olfactory bulb (Belluardo et al., 2008; Chen et al., 2007; Jin et al., 2003; Kuhn et al., 1997). Our group has contributed by showing that FGF2 and its receptor are expressed in neurogenic regions with FGF-2 localized in GFAP-positive cells, and that FGFR1 is expressed both in proliferating precursor nestin-positive cells of the SVZ (Mudo et al., 2007) and in self-renewing cells or stem cells (Frinchi et al., 2008). Functionally, FGFR1 may enhance proliferation of progenitor cells after nicotine treatment inducing upregulation of FGF2 (Belluardo et al., 2008; Mudo et al., 2007).

Giving the role of neurotrophic factors in neurogenesis, the age-dependent decline of progenitor or precursor cells proliferation (Belluardo et al., 2008; Cameron and McKay, 1999; Hattiangady and Shetty, 2008; Jin et al., 2003; Maslov et al., 2004; Rao et al., 2006; Tropepe et al., 1997) has been attributed to reduced levels of trophic support (Hallbergson et al., 2003). Previously, we have examined the potential involvement of the neurotrophic factor system FGF-2/FGFR1 in aging decline of precursor cell proliferation, and we could show that both FGF2 and FGFR1 expression levels do not change during aging. This result excludes that reduced levels FGF2/FGFR1 trophic system could be involved in the decline of progenitor/ precursor cells proliferation in aging.

Basically, FGF2 binding to FGFR1, which is facilitated by heparin or heparan sulfate proteoglycan, induces receptor dimerization, and activation of the intracellular tyrosine kinase domain by autophosphorylation of tyrosines. In the present study we examined the levels of phosphorylated FGFR1 and we 
could show that basal FGFR1 autophosphorylation levels in the SVZ do not change during aging. It is known that FGFR1 autophosphorylation is followed by activation of downstream signaling cascades that include Ras-MAPK/Erk1/2, PLC-PKC, PI3KAkt, and p38 MAPK pathways (Boilly et al., 2000; Eswarakumar et al., 2005; Raffioni et al., 1999), which participate in the regulation of diverse processes, such as cell growth and differentiation, cell metabolism, and cell survival (Eswarakumar et al., 2005). Among these intracellular signaling pathways, Erk1/2 and PLC $\gamma 1$ have been identified as distinct regulators of adult neuronal stem cell self-renewal in response to FGF-2. Erk1/2 pathway mediates both the proliferation and anti-neuronal differentiation effects of FGF-2, whereas PLC $\gamma 1$ maintains the adult neuronal stem cells characteristics and developmental potentials of adult neuronal stem cells for neuronal and oligodendroglial differentiation (Mohammadi et al., 1992; Schlessinger, 2000). In our work, we also provided evidence that Erk1/2 and PLC $\gamma 1$ cell signaling linked to FGFR1 autophosphorylation do not change their activation levels in the SVZ during aging.

Additionally, since it has been reported that progenitor cells decrease with age, as do transitory amplifying progenitor cells, while both SVZ astrocytes and adjacent ependymal cells remain relatively constant (Luo et al., 2006), we also investigated the proliferation level of self-renewing progenitor cells. These cells, as above mentioned, express FGFR1, and we found that apparently they do not show significant changes, at least in their ability to proliferate.

Taken together the present results indicate that the FGF-2/ FGFR1 trophic system expression level, and its basal activation in the SVZ of aged rats, do not account for the age-dependent decline of precursor cell proliferation in the rat brain.

\section{Experimental procedures}

\subsection{Animals}

The study was performed in young adult ( 3 months old) and aged (20 months old) male Wistar rats obtained from our animal facility. The rats were housed under alternating $12 \mathrm{~h}$ periods of light and darkness in a temperature $\left(24 \pm 2^{\circ} \mathrm{C}\right)$ and humidity-controlled room. Procedures involving animals and their care were conducted in conformity with the institutional guidelines that are in compliance with national and international laws and policies (EEC Council Directive $86 / 609$, OJ L 358,1, Dec. 12,1987; NIH Guide for the Care and Use of Laboratory Animals, NIH Publication no. 80-23, 1985 and Guidelines for the Use of Animals in Biomedical Research, Thromb. Haemost. 58, 1078-1084,1987). All efforts were made to minimize the number of animals used and all experiments were approved by the local ethical committee.

\subsection{Preparation and labeling of riboprobes}

The preparation of FGF-2 and its receptor FGFR-1 probes was carried out as previously reported (Belluardo et al., 2004). The FGFR-1 cRNA probe was prepared from a 220-bp-long cDNA fragment cloned into the Sma site of pBluescript KS1 (Stratagene, San Diego, CA, USA), encoding the leader sequence and entering 24 nucleotides into the first immunoglobulin-like domain of the gene sequence reported by (Safran et al., 1990). The plasmid was linearized with PstI and used as a template for T7 RNA polymerase to generate the antisense probe or was linearized with BamHI and transcribed with T3 RNA polymerase to generate the sense probe. For the in situ hybridization study of FGF-2 mRNA expression, a SmaI/XhoI fragment from a rat FGF-2 cDNA clone which includes most of the coding regions for the mature FGF-2 peptide, was subcloned into the vector Bluescript/SK ${ }^{+}$(Stratagene). Sense and antisense RNA sequences were transcribed from the linearized FGF-2/Bluescript subclone using T7 and T3 RNA polymerases to generate the antisense and sense probes, respectively.

\subsection{In situ hybridization}

For the in situ hybridization, serial sagittal cryostat sections $(14 \mu \mathrm{m})$ were prepared using for all rats the left part of brain at lateral $2.60-2.10 \mathrm{~mm}$ level, based on the use of the atlas of Paxinos and Watson (1998). For this investigation four young adult and four old rat brains were used. The in situ hybridization procedure was performed to examine the expression of FGF-2 and its receptor FGFR-1 mRNAs in the SVZ. Rats were killed under deep anesthesia and following perfusion with $300 \mathrm{ml}$ of phosphate buffer (PB) brain was rapidly frozen in cooled isopentane and stored at $-70^{\circ} \mathrm{C}$ until use. Tissue sections were processed for in situ hybridization as previously described by (Belluardo et al., 2005). Following fixation in $4 \%$ paraformaldehyde for $15 \mathrm{~min}$, slides were rinsed twice in phosphatebuffered saline (PBS) and once in distilled water. Tissue was deproteinated in $0.2 \mathrm{M} \mathrm{HCl}$ for $10 \mathrm{~min}$, acetylated with $0.25 \%$ acetic anhydride in $0.1 \mathrm{M}$ ethanolamine for $20 \mathrm{~min}$, and dehydrated with increasing concentrations of ethanol. Slides were incubated for $16 \mathrm{~h}$ in a humidified chamber at $52{ }^{\circ} \mathrm{C}$ with $8 \times 10^{5} \mathrm{cpm}$ probe in $70 \mu \mathrm{l}$ hybridization cocktail $(50 \%$ formamide, 20 mM Tris-HCl pH 7.6, 1 mM EDTA pH 8.0, 0.3 M NaCl, 0.1 M dithiothreitol, $0.5 \mu \mathrm{g} / \mathrm{ml}$ yeast tRNA, $0.1 \mu \mathrm{g} / \mathrm{ml}$ poly-A-RNA, $1 \times$ Denhardt's solution, and 10\% dextran sulfate), washed twice in $1 \times \mathrm{SSC}(1 \times \mathrm{SSC}=150 \mathrm{mM} \mathrm{NaCl}, 15 \mathrm{mM}$ sodium citrate, $\mathrm{pH} 7.0)$ at $62{ }^{\circ} \mathrm{C}$ for $15 \mathrm{~min}$, and then in formamide:SSC $(1: 1)$ at $62^{\circ} \mathrm{C}$ for $30 \mathrm{~min}$. After an additional wash in $1 \times$ SSC at $62^{\circ} \mathrm{C}$, singlestranded RNA was digested by RNAse treatment $(10 \mu \mathrm{g} / \mathrm{ml})$ for $30 \mathrm{~min}$ at $37^{\circ} \mathrm{C}$ in $0.5 \mathrm{M} \mathrm{NaCl}, 20 \mathrm{mM}$ Tris- $\mathrm{HCl} \mathrm{pH} \mathrm{7.5,} 2 \mathrm{mM}$ EDTA. Slides were washed twice with $1 \times \mathrm{SSC}$ at $62^{\circ} \mathrm{C}$ for $30 \mathrm{~min}$ before dehydration in ethanol and air-drying. For cell localization of mRNA, hybridized sections were coated with Emulsion Type NTB (Kodak, Rochester, NY, USA, cat. num.8895666) diluted in water (1:1) and stored in desiccated light-tight boxes at $4{ }^{\circ} \mathrm{C}$ for 4 weeks. Slides were developed with D19 (EastmanKodak), fixed with Al-4 (Agfa Gevaert, Kista, Sweden), and counterstained with Cresyl Violet. A control of the hybridization specificity of the cRNA riboprobes was performed by using sense ${ }^{35}$ S-labeled riboprobes. Semiquantitative data on mRNA levels of FGF-2 or FGFR1 in the SVZ were obtained by measuring the optical density of the labeling on the film autoradiograms using a PC version of the NIH Image software (http://rsb.info.nih.gov/ nih-image).

\subsection{Western blotting}

SVZ of both sides for each brain of four young adult and four old rats was rapidly dissected under stereomicroscopy as 
follow described. A thick brain coronal section, including the lateral ventricle, was made using a brain slicer (B-0.80 to $\mathrm{B}+1.70 \mathrm{~mm}$ (Paxinos and Watson, 1998), and all the corresponding SVZ area was exposed and scraped with a small knife. The tissue scraped was frozen and subsequently processed for Western blotting analysis. The tissue was homogenized in cold buffer containing $320 \mathrm{mM}$ sucrose, 2 mM EDTA pH 7.5, protease inhibitor cocktail (Sigma-Aldrich, cat. num P8340), phosphatase inhibitor cocktail 2 (SigmaAldrich, cat. num P5726). The homogenate was left on ice for $30 \mathrm{~min}$ and then centrifuged at $10,000 \mathrm{~g}$ for $15 \mathrm{~min}$ at $4^{\circ} \mathrm{C}$. The supernatant was collected and stored at $-20^{\circ} \mathrm{C}$ and an aliquot taken for protein determination by the method of Lowry et al. (1951). The supernatant samples (50 $\mu \mathrm{g}$ per lane) and molecular weight biotinylated markers (RPN2107, GE Healthcare Europe $\mathrm{GmbH}$, Milan Italy), were run on $10 \%$ or $6 \%$, for FGF2 and for pERK1/2 and pPLC $\gamma 1$ respectively, polyacrylamide gel at $100 \mathrm{~V}$ and electrophoretically transferred onto nitrocellulose membrane (RPN303E, Hybond-C-extra, GE Healthcare Europe $\mathrm{GmbH}$, Milan Italy). Following $1 \mathrm{~h}$ of incubation with $5 \%$ nonfat milk, the membrane was incubated overnight at $+4{ }^{\circ} \mathrm{C}$ with rabbit anti-FGF-2 polyclonal antibody (sc-79, Santa Cruz Biotechnology) used at a dilution of 1:1000, or rabbit antiPhospho-p44/42 (ERK1/2) (Thr202/Tyr204) antibody (\#9101 Cell Signaling) diluted 1:1000, or Phospho-PLC $\gamma 1$ (Tyr783) antibody (\#2821 Cell signaling) diluted 1:1000. The pellet was resuspended in RIPA buffer, left on ice for $30 \mathrm{~min}$. and then an aliquot taken for protein determination by the method of Lowry et al. (1951). The pellet samples $(200 \mu \mathrm{g})$ were incubated O/N with goat anti-FGFR1 (sc-31169, Santa Cruz Biotechnology) polyclonal antibody in $50 \mathrm{mM}$ TrisHCl pH7.4 e $150 \mathrm{mM} \mathrm{NaCl}$. Thereafter, samples were incubated with $50 \mathrm{mM}$ TrisHCl pH7.4, $150 \mathrm{mM} \mathrm{NaCl}$ e 1\%SDS for $30 \mathrm{~min}$ and then resuspended in $50 \mathrm{mM}$ TrisHCl pH7.4, $150 \mathrm{mM} \mathrm{NaCl}$ e 0.1\%SDS and immunoprecipitated with protein A/G PLUS-Agarose (sc-2003 Santa Cruz Biotechnology). Proteins immunoprecipitated were run on $7 \%$ polyacrylamide gel. Following $1 \mathrm{~h}$ of incubation with $5 \%$ non-fat milk, the membranes were incubated overnight at $+4{ }^{\circ} \mathrm{C}$ with goat anti-FGFR1 (sc-31169, Santa Cruz Biotechnology) polyclonal antibody, for FGFR1 protein quantification, or with mouse anti-phosphotyrosin (05-321 Upstate) diluted 1:2000 for pFGFR1 quantification. After washing the membranes were incubated for $1 \mathrm{~h}$ at room temperature with antirabbit IgG horseradish peroxidase-conjugated diluted 1:8000 (Sc 2054, Santa Cruz Biotechnology, Inc. Heidelberg, Germany), or with rabbit anti-goat IgG horseradish peroxidase-conjugated diluted 1:7000 ( sc-27-68 Santa Cruz Biotechnology), or with goat anti-mouse IgG horseradish peroxidase-conjugated diluted 1:7000 (sc-2005 Santa Cruz Biotechnology). $\beta$-actin was used as internal standard and mouse monoclonal antibody anti- $\beta$-actin was used at 1:5000 dilution (sc-47778 Santa Cruz Biotechnology).

In order to determine if the antibody anti-phosphotyrosin binds phosphorylated FGFR1 protein, sister membrane with representative samples were incubated over night at $37^{\circ} \mathrm{C}$ in NEBuffer 1× (NaCl $100 \mathrm{mM}$, Tris-HCl $50 \mathrm{mM}, \mathrm{MgCl}_{2} 10 \mathrm{mM}$, dithiothreitol $1 \mathrm{mM}, \mathrm{pH}$ 7.9) with or without $1 \%$ calf intestinal alkaline phosphatase (CIP, cat.\# M0290S, New England Biolabs, Beverly, MA, USA). After this incubation membranes were processed for pFGFR1 detection. Immuno-complexes were visualized with chemiluminescence reagent (RPN2108, GE Healthcare Europe $\mathrm{GmbH}$, Milan Italy) according to the manufacturer's instructions. The Hyperfilm ECL-films 28906837, GE Healthcare Europe $\mathrm{GmbH}$, Milan Italy) were developed using Kodak developer and fixer (catalog No. 1900984 and 1902485, Kodak GBX, Eastman Kodak)., and the densitometric evaluation of bands was performed by measuring the optical density (O.D.) using the ImageJ software (Rasband, W.S., ImageJ, U. S. National Institutes of Health, Bethesda, Maryland, USA, http://rsb.info.nih. gov/ij/, 1997-2009).

\subsection{BrdU immunolabeling and evaluation of BrdU-positive cells}

Four young adult and four old rats were injected intraperitoneally (i.p.) with $80 \mathrm{mg} / \mathrm{kg}$ of bromodeoxyuridine (BrdU) (B5002, SigmaAldrich Co., St. Louis, MO) three times at 0, 12 and $24 \mathrm{~h}$ respectively, and were killed after 21 days in order to evaluate the BrdU-labeled cells. At the scheduled time-point rats under deep anesthesia with chloral hydrate (60 mg/kg i.p; Merck) were transcardially perfused with phosphate buffer (PB) for $5 \mathrm{~min}$. Brains were rapidly frozen in cooled isopentane and stored at $-70^{\circ} \mathrm{C}$ until use. Brains were processed for BrdU immunohistochemistry as described in Mudo et al. (Mudo et al., 2007). The number of BrdU labeled cells was estimated by counts made on systematic sampling of brain sections (total of 10 sections of $14 \mathrm{~mm}$ ), every third section, along the lateromedial axis of left brain at lateral ventricle level (lateral $2.30-1.80 \mathrm{~mm}$ ), according to the atlas of Paxinos and Watson (1998) BrdU-positive cells were counted along the entire lateral wall of the lateral ventricle for SVZ. All the counts were carried out in a double blind manner, by mean of both optical counts and counts via the computerized image analysis software (IAS-Counter, Delta-Sistemi, Roma, Italy). Optical counts were performed using a Leica microscope and 100x magnification. Computerized image analysis was performed using software coupled to a Leica microscope equipped with digital video camera. Both count procedures produced comparable results and therefore we reported those obtained by optical count. Although, the count of BrdU positive cells was based on sampled brain sections that covered almost all the SVZ of left part of brain, we do not report the absolute number of proliferating cells in the entire extension of SVZ of the lateral ventricle. Details on the numerical density of BrdU labeled cells calculation are described in Mudò et al. (2007).

\subsection{Statistical analysis}

All data were analyzed in Prism 4 software (Graph-Pad, San Diego, CA), using t-test analysis, and $P<0.05$ was considered to be significant. Data are presented as mean \pm SEM from at least three independent experiments performed in triplicate $(n=8$ 12, per comparison).

\section{Acknowledgments}

This work was supported by grants from "Progetti di Ateneo", University of Palermo. MF, VDL and MO are supported by Ateneo PhD-Grant, University of Palermo. 


\section{R E F E R E N C E S}

Abrous, D.N., Koehl, M., Le, M.M., 2005. Adult neurogenesis: from precursors to network and physiology. Physiol. Rev. 85, 523-569.

Belluardo, N., Mudo, G., Blum, M., Itoh, N., Agnati, L., Fuxe, K., 2004. Nicotine-induced FGF-2 mRNA in rat brain is preserved during aging. Neurobiol. Aging 25, 1333-1342.

Belluardo, N., Olsson, P.A., Mudo', G., Sommer, W.H., Amato, G., Fuxe, K., 2005. Transcription factor gene expression profiling after acute intermittent nicotine treatment in the rat cerebral cortex. Neuroscience 133, 787-796.

Belluardo, N., Mudo', G., Bonomo, A., Di Liberto, V., Frinchi, M., Fuxe, K., 2008. Nicotine-induced fibroblast growth factor-2 restores the age-related decline of precursor cell proliferation in the subventricular zone of rat brain. Brain Res. 1193, 12-24.

Boilly, B., Vercoutter-Edouart, A.S., Hondermarck, H., Nurcombe, V., Le Bourhis, X., 2000. FGF signals for cell proliferation and migration through different pathways. Cytokine Growth Factor Rev. 11, 295-302.

Cameron, H.A., McKay, R.D., 1999. Restoring production of hippocampal neurons in old age. Nat. Neurosci. 2, 894-897.

Chen, K., Henry, R.A., Hughes, S.M., Connor, B., 2007. Creating a neurogenic environment: the role of BDNF and FGF2. Mol. Cell. Neurosci. 36, 108-120.

Craig, C.G., Tropepe, V., Morshead, C.M., Reynolds, B.A., Weiss, S., van der Kooy, D., 1996. In vivo growth factor expansion of endogenous subependymal neural precursor cell populations in the adult mouse brain. J. Neurosci. 16, 2649-2658.

Doetsch, F., Garcia-Verdugo, J.M., Alvarez-Buylla, A., 1999. Regeneration of a germinal layer in the adult mammalian brain. Proc. Natl. Acad. Sci. U. S. A. 96, 11619-11624.

Eswarakumar, V.P., Lax, I., Schlessinger, J., 2005. Cellular signaling by fibroblast growth factor receptors. Cytokine Growth Factor Rev. 16, 139-149.

Frinchi, M., Bonomo, A., Trovato-Salinaro, A., Condorelli, D.F., Fuxe, K., Spampinato, M.G., Mudo, G., 2008. Fibroblast growth factor-2 and its receptor expression in proliferating precursor cells of the subventricular zone in the adult rat brain. Neurosci. Lett. 447, 20-25.

Garcia-Verdugo, J.M., Doetsch, F., Wichterle, H., Lim, D.A., Alvarez-Buylla, A., 1998. Architecture and cell types of the adult subventricular zone: in search of the stem cells. J. Neurobiol. 36, 234-248.

Gritti, A., Frolichsthal-Schoeller, P., Galli, R., Parati, E.A., Cova, L., Pagano, S.F., Bjornson, C.R., Vescovi, A.L., 1999. Epidermal and fibroblast growth factors behave as mitogenic regulators for a single multipotent stem cell-like population from the subventricular region of the adult mouse forebrain. J. Neurosci. 19, 3287-3297.

Hallbergson, A.F., Gnatenco, C., Peterson, D.A., 2003. Neurogenesis and brain injury: managing a renewable resource for repair. J. Clin. Invest. 112, 1128-1133.

Hattiangady, B., Shetty, A.K., 2008. Aging does not alter the number or phenotype of putative stem/progenitor cells in the neurogenic region of the hippocampus. Neurobiol. Aging 29, 129-147.

Jin, K., Sun, Y., Xie, L., Batteur, S., Mao, X.O., Smelick, C., Logvinova, A., Greenberg, D.A., 2003. Neurogenesis and aging: FGF-2 and HB-EGF restore neurogenesis in hippocampus and subventricular zone of aged mice. Aging Cell 2, 175-183.
Kuhn, H.G., Winkler, J., Kempermann, G., Thal, L.J., Gage, F.H., 1997. Epidermal growth factor and fibroblast growth factor-2 have different effects on neural progenitors in the adult rat brain. J. Neurosci. 17, 5820-5829.

Lowry, O.H., Rosebrough, N.J., Farr, A.L., Randall, R.J., 1951. Protein measurement with the Folin phenol reagent. J. Biol. Chem. 193, 265-275.

Luo, J., Daniels, S.B., Lennington, J.B., Notti, R.Q., Conover, J.C., 2006. The aging neurogenic subventricular zone. Aging Cell 5, 139-152.

Maslov, A.Y., Barone, T.A., Plunkett, R.J., Pruitt, S.C., 2004. Neural stem cell detection, characterization, and age-related changes in the subventricular zone of mice. J. Neurosci. 24, 1726-1733.

Mohammadi, M., Dionne, C.A., Li, W., Li, N., Spivak, T., Honegger, A.M., Jaye, M., Schlessinger, J., 1992. Point mutation in FGF receptor eliminates phosphatidylinositol hydrolysis without affecting mitogenesis. Nature 358, 681-684.

Mudo, G., Belluardo, N., Mauro, A., Fuxe, K., 2007. Acute intermittent nicotine treatment induces fibroblast growth factor- 2 in the subventricular zone of the adult rat brain and enhances neuronal precursor cell proliferation. Neuroscience 145, 470-483.

Ohkubo, Y., Uchida, A.O., Shin, D., Partanen, J., Vaccarino, F.M., 2004 Fibroblast growth factor receptor 1 is required for the proliferation of hippocampal progenitor cells and for hippocampal growth in mouse. J. Neurosci. 24, 6057-6069.

Paxinos, G., Watson, C., 1998, The Rat Brain in Stereotaxic Coordinates 4th ed. New York, Academic Press, New York.

Raffioni, S., Thomas, D., Foehr, E.D., Thompson, L.M., Bradshaw, R.A., 1999. Comparison of the intracellular signaling responses by three chimeric fibroblast growth factor receptors in PC12 cells. Proc. Natl. Acad. Sci. U. S. A. 96, 7178-7183.

Rao, M.S., Hattiangady, B., Shetty, A.K., 2006. The window and mechanisms of major age-related decline in the production of new neurons within the dentate gyrus of the hippocampus. Aging Cell 5, 545-558.

Richards, L.J., Kilpatrick, T.J., Bartlett, P.F., 1992. De novo generation of neuronal cells from the adult mouse brain. Proc. Natl. Acad. Sci. U. S. A. 89, 8591-8595.

Safran, A., Avivi, A., Orr-Urtereger, A., Neufeld, G., Lonai, P., Givol, D., Yarden, Y., 1990. The murine flg gene encodes a receptor for fibroblast growth factor. Oncogene 5, 635-643.

Schlessinger, J., 2000. Cell signaling by receptor tyrosine kinases. Cell 103, 211-225

Tropepe, V., Craig, C.G., Morshead, C.M., van der Kooy, D., 1997. Transforming growth factor-alpha null and senescent mice show decreased neural progenitor cell proliferation in the forebrain subependyma. J. Neurosci. 17, 7850-7859.

Wagner, J.P., Black, I.B., DiCicco-Bloom, E., 1999. Stimulation of neonatal and adult brain neurogenesis by subcutaneous injection of basic fibroblast growth factor. J. Neurosci. 19, 6006-6016.

Yoshimura, S., Takagi, Y., Harada, J., Teramoto, T., Thomas, S.S., Waeber, C., Bakowska, J.C., Breakefield, X.O., Moskowitz, M.A. 2001. FGF-2 regulation of neurogenesis in adult hippocampus after brain injury. Proc. Natl. Acad. Sci. U. S. A. 98, 5874-5879.

Zhao, C., Deng, W., Gage, F.H., 2008. Mechanisms and functional implications of adult neurogenesis. Cell 132, 645-660.

Zheng, W., Nowakowski, R.S., Vaccarino, F.M., 2004. Fibroblast growth factor 2 is required for maintaining the neural stem cell pool in the mouse brain subventricular zone. Dev. Neurosci. 26, 181-196. 